\title{
THE ROLE OF A NOVEL VH SEQUENCE (V11) IN THE FORMATION OF ANTI-PHOSPHOCHOLINE ANTIBODIES*
}

\author{
Jacqueline W. Pierce, Susan Hudak and J. Latham Claflin \\ Program in Cellular and Molecular Biology and Department of Microbiology and Immunology, The \\ University of Michigan Medical School, Ann Arbor, MI 48109, U.S.A
}

(First received 29 June 1983; accepted in revised form 22 September 1983)

\begin{abstract}
The immune response to phosphocholine $(\mathrm{PC})$ in mice is highly restricted. Most anti-PC antibodies use heavy-chain variable-region (VH) sequences derived from single VH gene segment, $V I$. In order to investigate whether a highly homologous $\mathrm{VH}$ gene segment, $V I I$, could contribute to the formation of PC-binding antibodies, we carried out chain recombination experiments with M47A, a non-PC binding myeloma protein whose $\mathrm{H}$-chain is encoded by the VII gene segment, and two PC-binding antibodies, HP101.6G6 (HP6G6) and M511. The H-chains from the non-PC-binding myeloma protein, M47A, formed a functional PC-binding site when paired with L-chains from both PC-binding antibodies. These results suggest that a second VII gene segment, V11, could theorctically be used to form PC-binding antibodies. In addition, these results provide direct evidence that a single H-chain can be used in combinatorial association with different L-chains to form antibodies of differing specificities.
\end{abstract}

\section{INTRODUCTION}

The role of germline, somatic and combinatorial mechanisms is generating immunoglobulin diversity has been studied extensively in the antibody response to PC† (Crews et al., 1981., Gearhart et al., 1981; Selsing and Storb, 1981). The response to this small hapten is highly restricted (Claflin and Rudikoff, 1976) and sequence information on murine mycloma and hybridoma proteins has shown that most anti-PC antibodies use a single type of $\mathrm{H}$-chain sequence (VH4) which is paired with one of three different types of L-chain sequences (VK8, VK22 or VK24) (Barstad et al., 1978). Crews et al. (1981) identified a family of four highly homologous $\mathrm{VH}$ segments in BALB/c mice (designated $V I, V I l, V I 3$ and $V 3$ ), and they have clearly shown that most anti-PC antibodies use VH sequences that are somatically derived from a single member of this $\mathrm{VH}$ gene family, V1. Recently, however, several observations have suggested that other members of this VH family (VII or VI3) might be used to generate $\mathrm{H}$-chains of $\mathrm{PC}$-binding antibodies. Clarke et al. (1982) reported the sequence of a monoclonal anti-PC antibody of $\mathrm{CBA} / \mathrm{J}$ origin, HP101.6G6 (HP6G6), which appears to be derived from the $\mathrm{CBA} / \mathrm{J}$ homologue of $V 11$. A second exam-

*This work was supported by NIH grants AI 12533(JLC) and GM 07315 (JWP).

†Abbreviations: BSA, bovinc serum albumin; $H$, heavy; $L$, light; PC, phosphocholine; PC-BGG, PC-bovine gamma globulin; $V I$ and $V l$, gene and gene product of a VH segment. ple of an anti-PC antibody derived from a gene other than $V l$ is the BALB/c hybridoma protein HPCG 15 , which has an $N$-terminal sequence that is more closely related to V11 or V13 than it is to V1 (Gearhart et al., 1981). There is no known example of an anti-PC antibody that uses the precise V11 or V13 germline sequence. The question we wished to address was whether the germline $\mathrm{V} 11 \mathrm{VH}$ sequence could contribute to the formation of anti-PC antibodies. Specifically, could an H-chain having the germline V11 sequence pair with an appropriate L-chain to form a functional PC-binding site? An $\mathrm{H}$-chain which has the V11 germline sequence has been observed in the non-PC-binding myeloma protein M47A (Robinson and Appella, 1979). In order to examine the possible role of $\mathrm{V} 11$ sequences in the formation of a PC-binding site, we carried out chain recombination experiments between the $\mathrm{H}$-chain of M47A and L-chains from two PC-binding antibodies.

The prediction that the M47A H-chain might be able to participate in formation of a PC-binding site was based on several observations. While the M47A VH sequence contains substitutions which are located at or near the so-called "contact residues" (Padlan $c t$ al., 1976), many of these substitutions (positions 30 , 32,35 and 51) have been observed in the PC-binding protein HP6G6 and thus are not incompatible with PC-binding (see Fig. 1). The entire $\mathrm{H}$-chain variable region of M47A is notably similar to the $\mathrm{VH}$ region of HP6G6. The M47A sequence differs from HP6G6 at seven positions in the $\mathrm{VH}$ segment. The M47A DH segment is the same length as that of HP6G6 and the 


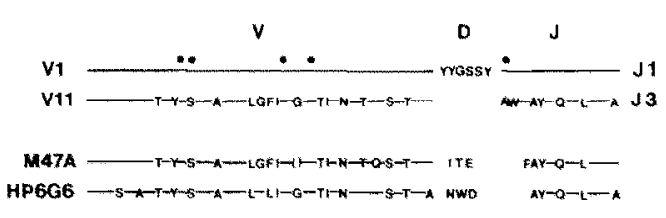

Fig. 1. Comparison of complete VH region sequences of M47A and HP6G6 with BALB/C germline encoded sequences. The translated sequences of $B A L B / C$ gene segments $V /$ and $V I /$ (top two lines) given in single-letter amino acid code were determined by Crews et al. (1981). The translated DII sequence (Kurosawa and Tonegawa, 1982), 11 sequence (Early et al., 1980) and $\mathbf{J} 3$ sequence (Gough and Bernard, 1981) are also shown. Solid line indicates identity with the translated $\mathrm{Vl}$ or $\mathrm{Jl}$ sequence. Amino acid sequence of M47A VH region (Robinson and Appella, 1979) and HP6G6 VH regions (Clarke et al., 1982) (bottom two lines) are compared with the BALB/c germline encoded sequences. Substitutions from V1 and JI are noted. Contact residues according to Padlan et al. (1976) are indicated with a solid circle.

M47A JH sequence is encoded by the same JH gene as the IIP6G6 JH sequence (JII3). In these experiments, the M47A $\mathrm{H}$-chain was paired with either HP6G6 L-chain or M511 L-chain. Since the M47A VH sequence is most closely related to the HP6G6 VH sequence, we predicted that the HP6G6 L-chain would be the most likely L-chain to pair with M47A $\mathrm{H}$-chain. The M511 L-chain was selected because it has an $N$-terminal sequence identical to HP6G6 L-chain (Clarke S., personal communication). Our goal was to determine whether M47A $\mathrm{H}$-chains could form a functional PC-binding site with either of these $\mathrm{L}$-chains. We measured $\mathrm{PC}$-binding activity in $\mathrm{H}$ - and $\mathrm{L}$-chain mixtures and not the precise extent of $\mathrm{H}-\mathrm{L}$ reassociation because the requirements for reconstitution of binding activity are more rigorous than the requirements for formation of a stable recombinant molecule (Barstad et al.. 1978; Bridges and Little, 1971; Kranz and Voss, 1981; Manjula ot al., 1976). We show that the V11-derived M47A $H \cdot c h a i n$ formed a functional PC-binding recombinant when paired with L-chains from both HP6G6 and M511.

\section{MATERIALS AND METHODS}

\section{Myeloma and hybridoma proteins}

The myeloma cell line M47A was obtained from Litton Bionetics Inc. (Kensington, MD). M47A urinary protein was purified from the urine of $B A L B / C$ mice (Jackson Laboratory, Bar Harbor, ME) bearing subculaneous M47A tumors as described (Bevan, 1971). Urine was clarified by centrifugation $(300 \mathrm{~g})$, concentrated with sucrose and dialyzed extensively against distilled water and then against $0.04 M$ potassium phosphate buffer ( $\mathrm{pH} 8$ ). The M47A protein was then purified by elution from a DEAE-Sephadex column $(1.5 \times 55 \mathrm{~cm})$ in $0.04 \mathrm{M}$ potassium phosphate buffer ( $\mathrm{pH} \mathrm{8)}$ as described by Askonas and Williamson (1968). The PC-binding myeloma protein,
M511, and hybridoma protein HP6G6 were purified from tumor ascites by affinity chromatography on PC-Sepharose as described (Claftin and Cubberly. 1980).

\section{Anti-fidolypic antiserum: whit anti-M47A}

$A$ heterologous anti-idiotypic antiserum was made against the purified myeloma protein M47A. A rabbit was immunized intradermally (i.d.) with $1 \mathrm{mg} \mathrm{M47A}$ in CFA. Then. 2 weeks later, it received a secondary immunization of $1 \mathrm{mg}$ M47 A in saline (i.d.). Serum was obtained 8 days atter secondary immunization. The gamma globulin fraction was precipitated with $40^{\circ}$, ammonium sulfate and then dialyred aganst PBS. The antiserum was then absorbed by passage over a Sepharose immunoadsorbent column containing $\mathrm{BALB} / \mathrm{C}$ normal mouse serum (NMS). The $B A L B / C$ NMS had been previously absorbed on $\mathrm{PC}$ Sepharose to remove naturally occurring anti-PC antibodies. The anti-M47A was also absorbed on a Sepharose column to which M511. M167 and M603 myelona proteins had been coupled. Absorption of antiserum on these columns was designed to remove activity directed against NMS, the $x$ constant region. the kappa constant region and any variable-region determinants on M511, M/67 or M603. The specificity of this antiserum was tested by direct binding of radiolabelled myeloma proteins and by inhibition assay with radiolabelled M47A.

\section{$H$ - and L-chain separation}

$\mathrm{H}$ - and $\mathrm{L}$-chains were prepared from purified myeloma or hybridoma proteins as described by Bridges and Little (1971). A $1-\mathrm{ml}$ protein solution containing $50 \mathrm{mg}$ was dialyzed against $0.2 \mathrm{M}$ Tris $\mathrm{Cl}(\mathrm{pH} 8.2)$. $0.15 \mathrm{M} \mathrm{NaCl}$ and $0.002 \mathrm{M} \mathrm{Na}$ EDTA. Each protein was reduced with $0.01 \mathrm{M}$ dithiothreitol for $2 \mathrm{hr}$ and alkylated with $0.022 \mathrm{M}$ iodoacetamide for $15 \mathrm{~min}$. This reduction and alkylation procedure was performed twice. Samples were then dialyzed against $6 M$ urea and $I N$ acetic acid solvent before scparation of $\mathrm{H}$ - and L-chains by reverse flow chromatography on a G100 Sephadex column $(2.5 \times 100 \mathrm{~cm})$ in the ureat-acetic acid solvent. The M47A H-chain (mol. wt 40,000) and L-chain (mol. wt 23,000) were separated on a larger G100 Sephadex column $(2.5 \times 170 \mathrm{~cm})$. Separated M47A H-, M47A $\mathrm{L}-\mathrm{M} 511 \mathrm{H}$ - and $\mathrm{M} 511 \mathrm{~L}$-chains were stored at $4 \mathrm{C}$ in $6 M$ urea and $I N$ acetic acid until used in chain recombination experiments. The HP6G6 L-chain was dialyzed against $0.01 \mathrm{M}$ ammonium bicarbonate buffer and stored as lyophilized protein. Purified $\mathrm{H}$ - and L-chains were tested for purity by SDS-polyacrylamide gel electrophoresis (SDS-PAGE) as described by Laemmli (1970). The M47A H-, M511 H-and M511 L-chain samples were visualized by silver staining as described by Wray $o t$ al. (1981), M47A L- and HP6G6 L-chains were visualized on a separate gel by staining with $0.01^{\circ}$ Coomassie blue. 


\section{Chain reassociation}

Chain reassociation was performed as described by Bridges and Little (1971). H- and L-chains were mixed in $6 M$ urea and $1 N$ acetic acid at an $\mathrm{H}: \mathrm{L}$ absorbancy ratio $(280 \mathrm{~nm})$ of approximately $1: 1$ as indicated. Final protein concn was $50-200 \mu \mathrm{g} / \mathrm{ml}$. Reassociation was achieved by gradual stepwise dialysis of mixed chains against distilled water then PBS at $4 \mathrm{C}$. Control preparations of $\mathrm{H}$-chain alone or L-chain alone were treated similarly.

\section{Solid-phase radioimmunoassay (SRIA)}

Direct binding assay. Chain recombination mixtures were tested for their ability to bind ${ }^{125} \mathrm{I}$-labelled PC-BGG in an SRIA. PC-BGG was prepared as described (Clafin and Davie, 1975) and iodinated by the procedure of Greenwood et al. (1963). H-chains, $\mathrm{L}$-chains or $\mathrm{H}+\mathrm{L}$ chain mixtures were used to coat polyvinyl chloride microtiter wells (Dynatech Laboratories, Alexandria, VA) $(0.2 \mathrm{ml} /$ well $)$ for $6 \mathrm{hr}$ at $25 \mathrm{C}$ at concns indicated. Protein was aspirated and wells were washed 3 times with PBS. Wells were then saturated with $1 \%$ BSA in PBS for $1 \mathrm{hr}$. A $0.2 \mathrm{ml}$ solution of ${ }^{125}$ I-labelled PC-BGG $(50,000 \mathrm{cpm})$ in $1 \%$
BSA, PBS was added and wells were incubated for $12-14$ hr at $25^{\circ} \mathrm{C}$. Unbound $\mathrm{PC}-\mathrm{BGG}$ was removed by aspiration and wells were washed 3 times with PBS. The binding of ${ }^{125} \mathrm{I}-\mathrm{PC}-\mathrm{BGG}$ to protein-coated wells was assayed by counting individual wells in a Packard Auto-Gamma Scintillation Spectrometer. Duplicates were run for each binding assay.

Inhibition assay for idiotype. Rabbit anti-M47A antiserum at a 1:1000 dilution was used in a solidphase inhibition assay as described by Claflin and Davie (1975). Binding of ${ }^{125} \mathrm{I}$-labelled M47A $(50,000 \mathrm{cpm} / \mathrm{ml})$ in the presence of unlabelled inhibitor protein was measured

\section{RESULTS}

\section{Purification of $\mathrm{H}$ - and $\mathrm{L}$-chains}

The G100-Sephadex separation resulted in quantitative yields of $\mathrm{H}$ - and L-chains from each parent, including M47A, indicating that the unusual covalent bond between M47A H- and L-chains (Robinson and Appella, 1979) was efficiently reduced under these conditions. Results of an SDS-polyacrylamide gel of M47A H, MS11 $\mathrm{H}$ and M511 L are shown in Fig. 2. Titration of each sample at several concns showed

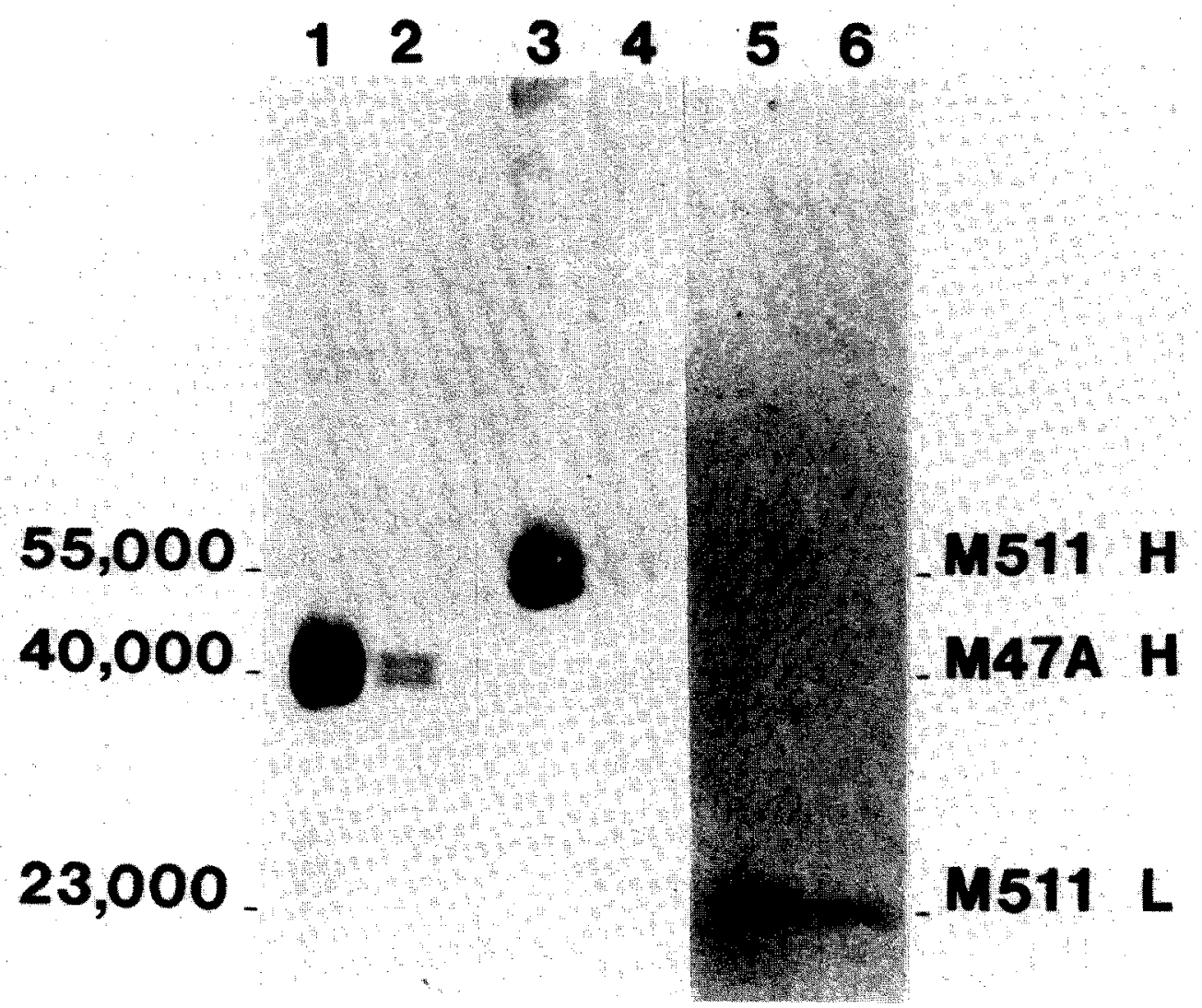

Fig. 2. SDS-PAGE analysis of separated $H$ - and L-chains. Separated $H$ - and $L$-chains were analyzed in a $10 \%$ polyacrylamide gel containing $0.1 \%$ SDS and $8 \mathrm{M}$ urea. Gel was run for $5 \mathrm{hr}$ at $20 \mathrm{~mA}$. Polypeptides were visualized using silver-staining procedure as described by Wray et at. (1981). Lane 1, M47A H: $5 \mu \mathrm{g}$. lane 2, M47A H: $1 \mu \mathrm{g}$ : lane $3, \mathrm{M} 511 \mathrm{H}: 8 \mu \mathrm{g}$ : lane 4, M511 H: $1.5 \mu \mathrm{g}$; lane 5 , M511 L: $1 \mu \mathrm{g}$; and lane 6. M511 L: $0.2 \mu \mathrm{g}$. 


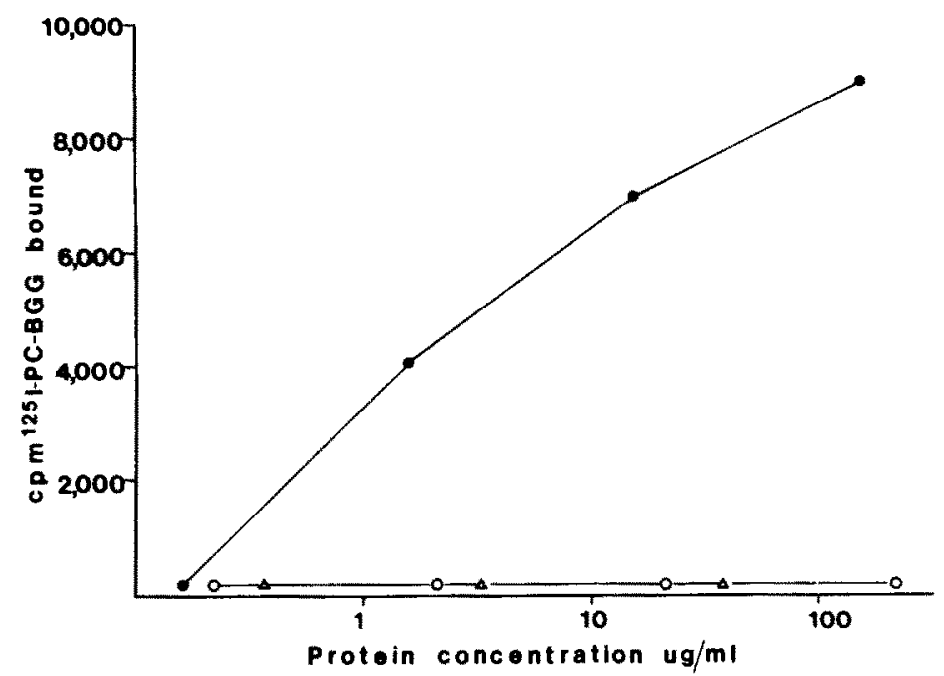

Fig. 3. Homologous recombination of M511 H and M511 L: direct hinding of ${ }^{225}$ I-PC-BGG. M51/ $H$-chains and M511 L-chains were mixed whle in urea-acetic acid solvent at an $H: L$ absorbance ratio at $280 \mathrm{~nm}$ of $1: 1$. Final protein conen after dialysis of $\mathrm{H}+\mathrm{L}$ mixture was $163 \mu \mathrm{g} / \mathrm{m} /$. Homologous mixture $(\mathrm{H}+\mathrm{L}), \mathrm{M} 511 \mathrm{H}$ or M511 L at concns indicated were tested for the ability to bind 125 -PC-BGG in a direct SRIA as described in Materials and Methods. Each point is the average of duplicate determinations. $\mathrm{M} 511 \mathrm{H}+\mathrm{M} 511 \mathrm{~L}(-\mathrm{M}-\mathrm{M} 11 \mathrm{H}(\mathrm{O}-\mathrm{O}), \mathrm{M} 511 \mathrm{~L}(\triangle-\triangle)$.

that individual chains contained less than 1\% contamination. The M47A H-chain had an apparent mol. wt of approximately 40,000 which is consistent with previous observations of Robinson and Appella (1979) who found that the M47A H-chain lacked the $\mathrm{CH} 3$ domain. Preparations of M47A L, HP6G6 H and HP6G6 $\mathrm{L}$ had less than $5 \%$ contamination as estimated from Coomassie blue stained SDS PAGE (data not shown).

\section{IIomologous chain mixtures}

The ability of separated chains to recombine and form functional molecules was first tested by mixing homologous chains, i.e. $\mathrm{H}$ - and L-chains derived from the same parental molecule. The M511 H-chain was mixed with M511 L-chain while in urea-acetic acid solvent, dialyzed and then tested for the ability to bind ${ }^{125} \mathrm{I}-\mathrm{PC}-\mathrm{BGG}$ as described in Materials and Methods. In these experiments, we were principally concerned with the reconstitution of functional binding sites and not the extent of $\mathrm{H}-\mathrm{L}$ association. Results of homologous recombination are shown in Fig. 3. The separated chains did not demonstrate any detectable binding activity. Thus, the purified chains did not contain any intact molecules or contaminating chains that could yield a detectable recombinant upon dialysis. The level of binding of the mixture of M511 H+M511 L was approximately $80 \%$ of the binding activity observed for the reduced and alkylated parent molecule. Thus, separated M5II $\mathrm{H}$ - and L-chains were capable of efficient recombination to form a functional PC-binding site.

Separated $\mathrm{H}$ - and $\mathrm{L}$-chains from the myeloma protein M47A were then tested for their ability to form a homologous recombinant. Since the M47A protein has no known binding activity, the ability to recombine was tested by the reconstitution of $M 47 \Lambda$ idiotypic determinants. The anti-M47A idiotypic antiserum used to monitor recombination reacted exclusively with M47A and showed no activity toward M511 $(\operatorname{IgA}, \kappa)$ or HP6G6 $(\operatorname{IgM}, k)$ which possess $\mathrm{CH}, \mathrm{CK}$ or $\mathrm{VH}$ regions similar to M47A (see Fig. 4). The homologous recombination mixture of M47A $\mathrm{H}+\mathrm{M} 47 \mathrm{~A} \mathrm{~L}$ inhibited binding of ${ }^{125} \mathrm{I}-\mathrm{M} 47 \mathrm{~A}$ (native) to this anti-idiotypic antiserum, and the level of inhibition was the same as that observed with a reduced and alkylated preparation of the parent M47A. Individual M47A H-chains or M47A Lchains showed some ability to inhibit; however, they had 4- to 18-fold lower activity, respectively, in this assay. These results demonstrate that the mixing of M47A $\mathrm{H}$ - and L-chains is accompanied by a reconstitution of idiotypic determinants indicating that M47A H and M47A $\mathrm{L}$ are able to recombine to form a molecule which is idiotypically similar to intact M47A.

\section{Heterologous chain mixtures}

To determine whether M47A H-chain, containing. V11-derived sequences, could form a functional recombinant with the L-chain from a PC-binding antibody, the M47A H-chain was paired with either the HP6G6 L-chain or the M511 L-chain. The first step in the heterologous recombination experiments was to demonstrate that the HP6G6 L-chain was functional. Homologous recombination between HP6G6 $\mathrm{H}$ and HP6G6 $\mathrm{L}$ did not result in formation of a functional molecule due to the insolubility of the HP6G6 H-chain. As an alternative approach, a preliminary experiment was performed which combined 


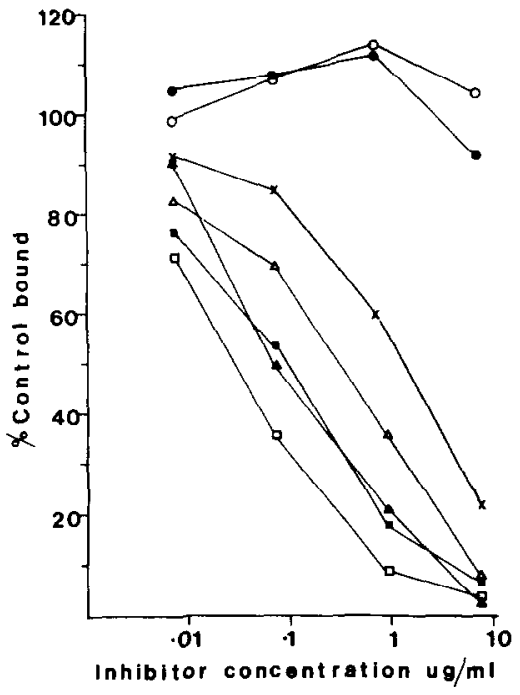

Fig. 4. Homologous recombination of M47A H and M47A L: expression of M47A idiotypic determinants. Inhibition SRIA as described in Materials and Methods was used to examine the expression of M47A idiotypic determinants on individual M47A H-chains, M47A L-chains or M47A $\mathrm{H}+\mathrm{L}$ mixture. M47A $\mathrm{H}$-chains were mixed with M47A L-chains in urea-acetic acid solvent at an $\mathrm{H}: \mathrm{L}$ absorbance ratio at $280 \mathrm{~nm}$ of $1: 2$. Final protein concn in $\mathrm{H}+\mathrm{L}$ mixture after dialysis was $65 \mu \mathrm{g} / \mathrm{ml}$. The binding of ${ }^{125} \mathrm{I}-\mathrm{M} 47 \mathrm{~A} \quad(50,000 \mathrm{cpm} / \mathrm{ml})$ to anti-M $47 \mathrm{~A}$ at $1: 1000$ was inhibited by unlabelled proteins as follows; HP6G6 (O-O), M511 (- ) M47A II-chain $(x-x)$, M47A L-chain $(\triangle-\triangle)$, M47A H + M47A L $(-\square)$, reduced + alkylated M47A $(\boldsymbol{\Delta}-\mathbf{A})$, intact M47A

$$
(\square-\square)
$$

HP6G6 L-chain with M511 H-chain. This H-chain, unlike HP6G6 $\mathrm{H}$-chain, retains its solubility when separated from the parent molecule. The result of heterologous recombination of M511 H and HP6G6 $\mathbf{L}$ is shown in Fig. 5A. The $\mathrm{H}+\mathbf{L}$ mixture showed significant PC-binding activity while individual $\mathrm{H}$ - or L-chains did not show any detectable binding. The activity observed with this heterologous recombination was similar to that seen in the homologous recombination of $\mathrm{M} 511 \mathrm{H}$ with $\mathrm{M} 511 \mathrm{~L}$ (compare Figs $5 \mathrm{~A}$ and 3 ).

When M47A $\mathrm{H}$ was paired with HP6G6 L-chain under identical experimental conditions a slightly different result was obtained (Fig. 5B). Individual Hor L-chains alone, treated the same as $\mathrm{H}+\mathrm{L}$ mixtures, showed no detectable activity. When M47A H-chains were mixed with HP6G6 L-chains, PCbinding activity was reconstituted. The control experiment of M47A H + M47A L did not show any PC-binding activity, indicating that the HP6G6 Lchain was necessary for the reconstitution of a functional binding site. It is important to note, however, that the level of $\mathrm{PC}$-binding which was reconstituted in the heterologous mixture of M47A H + HP6G6 L is less than $10 \%$ of the activity observed when M511
H-chain was used under identical conditions (compare Fig. 5A and B).

Further experiments pairing M47A H-chain with M511 L-chain gave results similar to those obtained with M47A H + HP6G6 L (see Fig. 5C). The PCbinding activity for the M47A $\mathrm{H}+\mathrm{M} 511 \mathrm{~L}$ mixtures was comparable to that of M47A H HP6G6 L. The ratio of $H: L(1: 1$ or $2: 1)$ had no apparent effect on the reconstitution of binding activity.

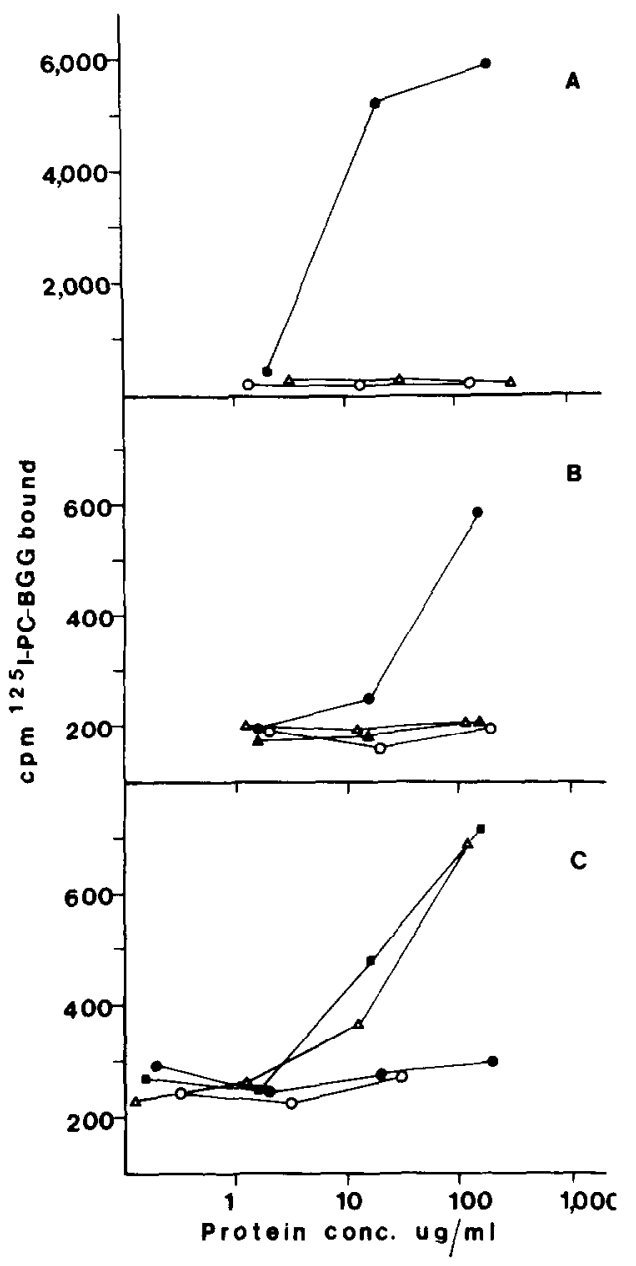

Fig. 5. Heterologous recombinations: direct binding of ${ }^{125} \mathrm{I}-\mathrm{PC}-\mathrm{BGG}$. Direct SRIA binding assay was used to examine the binding of ${ }^{125} \mathrm{I}-\mathrm{PC}-\mathrm{BGG}(250,000 \mathrm{cpm} / \mathrm{ml})$ to individual $\mathrm{H}$-chains, $\mathrm{L}$-chains or $\mathrm{H}+\mathrm{L}$ mixtures. Background counts bound in the absence of protein sample were approximately $200 \mathrm{cpm}$. Total cpm bound are indicated. (A) M511 H + HP6G6 L: M511 H-chains were mixed with HP6G6 L-chains at an H:L absorbance ratio at $280 \mathrm{~nm}$ of 1:1. Final protein concn after dialysis was $200 \mu \mathrm{g} / \mathrm{ml}$. M511

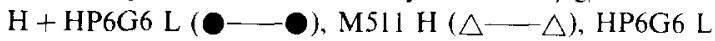
(O- $O$ ). (B) M47A H + HP6G6 L: M47A H-chains were mixcd with HPGG6 L-chains at an II : L absorbance ratio of $1: 1$. Final protein concn after dialysis was $173 \mu \mathrm{g} / \mathrm{ml}$. M47A $\mathrm{H}+\mathrm{HP} 6 \mathrm{G} 6 \mathrm{~L}(-\mathrm{C}), \mathrm{HP} 6 \mathrm{G} 6 \mathrm{~L}(\triangle--\triangle), \mathrm{M} 47 \mathrm{~A} \mathrm{H}$ (O-O). M47A H+M47A I, (A-A). (C) M47A $\mathrm{H}+$ M511 L: M47A H-chains were mixed with M511 L-chains at an $\mathrm{H}: \mathrm{L}$ absorbance ratio of either $1: 1$ or $2: 1$. Final protein concn was $125-180 \mu \mathrm{g} / \mathrm{ml}$. M47A $\mathrm{H}+\mathrm{M} 511$

L, 1:1 $(\triangle \longrightarrow \triangle)$; M47A H + M511 L, 2:1 ( $-\square)$; M47A H (- M ) M 11 L $\left(\mathrm{O}_{-}-\mathrm{O}\right)$. 


\section{DISCUSSION}

The goal of these experiments was to determine whether the germline $V 11$ sequence could participate in the formation of a PC-binding antibody. Our results show that the M47A H-chain, which contains the VIl germline sequence, is able to form a PCbinding site when paired with either HP6G6 L-chains or M511 L-chains. These data suggest that a second member of the PC VH gene family, VII, could theoretically be used to form PC-binding antibodies. Thus, the observation that most anti-PC antibodies use V1 or V1-derived sequences and not the V11 sequence cannot be attributed to the inherent inability of the VII sequence to cooperate in formation of a PC-binding site. The question of why the V1I germline sequence is not used to encode anti-PC antibodies cannot be answered simply. One likely possibility is that antibodies using V11 sequences may have a much lower affinity for PC than those that use $\mathrm{Vl}$ sequences. This might be predicted from the observation that HPCG 15, which appears to use a non-Vl sequence, has an affinity for $P C$ which is 10-fold lower than most anti-PC antibodies (Gearhart et al., 1981). A second reason why V1l germline sequences are not found in anti-PC antibodies may be that the VII sequence does not pair efficiently with the appropriate VK sequence. The precise sequence requirements for $\mathrm{VH}-\mathrm{VL}$ pairing have not been established. In murine anti-PC antibodies, Rudikoff et al. (1982) suggest that a glutamic acid residue at position 35 of the $H$-chain may interact with tyrosine at position 94 of the L-chain. These investigators noted that the $V /$ gene is the only member of this $V H$ family encoding glutamic acid at position 35 . The fact that the V11 and V13 VH sequences have a glutamic acid residue to serine substitution at this position could affect the ability of these $\mathrm{VH}$ sequences to pair efficiently with an appropriate L-chain; however, this serine substitution occurs in the proteins HP6G6 and HPCG15, indicating that this substitution does not preclude $\mathrm{H}-\mathrm{L}$ interaction. Preferential use of the $V l$ gene product to encode anti-PC antibodies may reflect the importance of residue 35 in the structure of the PC-binding site.

While our data show that the M47A chain is capable of forming a PC-binding site, they provide only limited information on the relative effectiveness of the VII germline sequence compared to V1 in formation of PC-binding antibodies. We observed that heterologous mixtures of M47A H-chain (V11) with HP6G6 L-chain showed less than $10 \%$ of the $\mathrm{PC}$-binding activity seen in a heterologous mixture of M511 H-chain (V1) with the same L-chain. This lower binding activity, however, may be due to several factors. Chain recombination experiments involving the M47A H-chain are complicated by the fact that the M47A myeloma protein is an $\operatorname{IgA}$ half-mer (one H-chain and one L-chain), it lacks the $\mathrm{CH} 3 \mathrm{H}$-chain domain and it contains an unusual covalent bond between the $\mathrm{H}$ - and L-chain (Mush- inski, 1971; Robinson and Appella, 1979). The lack of a $\mathrm{CH} 3$ domain should not affect the ability of M47A $H$ to pair with the L-chain since only VII-VK and $\mathrm{CH} 1-\mathrm{CK}$ interactions are involved in $\mathrm{H}-\mathrm{L}$ pairing (Alexandru et al., 1980; Klein et al. 1979). However, recombination involving the $\mathrm{M} 47 \mathrm{~A} \mathrm{H}$ chain would be expected to result in the formation of two-chain molecules rather than the usual four-chain molecules. In these experiments, we have not determined whether the lower binding activity observed with M47A H-chain mixtures reflects less efficient $\mathrm{H}-\mathrm{L}$ reassociation or the formation of a heterologous recombinant with a lower affinity for $\mathrm{PC}$. It is likely that both decreased $\mathrm{H}-\mathrm{L}$ pairing and lower affinily would be observed. The per cent $\mathrm{H}-\mathrm{L}$ reassociation observed might be influenced by the stability of two-chain molecules and by possible trace amounts of homologous M47A L-chain in the M47A H-chain sample that could compete with heterologous L-chain (Grey and Mannik, 1965). The fact that M47A H and HP6G6 $L$ recombinants exist as two-chain molecules should not affect the affinity of the binding site (Zack et al., 1981); however, monovalency may account for reduced binding observed in SRIA due to reduced avidity of these antibodies. Two-chain molecules cannot be affinity purified on PC-Sepharose (Zack $" t$ al., 1981). Thus, we could not study the affinity of M47A $\mathrm{H}+\mathrm{HP6G} 6 \mathrm{~L}$ recombinant molecules or the idiotypic properties of this heterologous recombinant because we were unable to purify sufficient material for these experiments.

Our data provide new information on the role of germline, somatic and combinatorial mechanisms in generating antibody diversity. The observation that the VII sequence could be used in anti-PC antibodies suggests that germline $\mathrm{VH}$ gene segments other than $V l$ may play a role in the immune response to $\mathrm{PC}$. Other investigators have reported that $\mathrm{PC}$-binding antibodies which use non-VI sequences (VH12) can be found in T15-suppressed mice (Kocher et al., 1980) and that a subset of T15 idiotype-negative antibodies in the memory response to $\mathrm{PC}-\mathrm{KLH}$ may use a VH sequence different from V1 (Chang ot al. 1982: Wicker et al., 1982). It would be interesting to investigate whether suppression of antibodies which utilize V1-encoded sequences would result in the usc of the less common anti-PC antibodies from the VII gene or other $\mathrm{VH}$ genes.

It is also possible that the germline $V / /$ sequence is not observed in the anti-PC response because substitutions in the VII sequence (similar to that seen in HPCG15 or HP6G6) may be required for the formation of a functional anti-PC antibody from this germline sequence. Somatic diversification has been suggested to account for increased affinity of $\lg (;$ anti-PC antibodies (Rodwell ef al., 1983). A similar finding has recently been reported for anti-arsonate antibodies (Rothstein and Gefter, 1983). It is possible that complementary substitutions in both VH and VL may be required for efficient PC-binding 
The role of combinatorial association in generating antibody diversity has been studied for many years. The chain recombination experiments presented here provide direct evidence for the role of combinatorial association in generating antibodies of different specificities. A single $\mathrm{H}$-chain, M47A $\mathrm{H}$, can pair with either M47A L or HP6G6 L to form antibodies with different specificities. Previous investigators have shown that the formation of functional antibodies through reassociation of heterologous $\mathrm{H}$ - and L-chains is quite restricted (Bridges and Little, 1971; Grey and Mannik, 1965; Kranz and Voss, 1981; de Preval and Fougereau, 1976). Functional heterologous recombinants have been formed between $\mathrm{H}$ - and L-chains derived from antibodies having highly homologous amino acid sequences. For example, heterologous recombination among functionally-related antibodies such as anti-galactan (Manjula et al, 1976), anti-inulin (Streefkerk et al., 1978), anti-H-2 (Bluestone et al., 1982) or anti-PC (Barstad et al., 1978; Hudak and Claflin, manuscript in preparation; Scher et al., 1971) antibodies can result in the formation of functional recombinant molecules. Recently, several observations have suggested that the same VH sequence may contribute to the formation of antibodies with different specificities. An example of overlapping $\mathrm{VH}$ repertoires may be seen in the anti-streptococcus group A carbohydrate antibody S8 which has an $\mathrm{N}$-terminal VH sequence very similar to the $\mathrm{V} 1$-encoded sequence of PC-binding antibodies (Capra et al., 1976; Crews et al., 1981). In addition, Staudt and Gerhard (1983) have recently reported that antibodies which bind the hemagglutinin (HA) protein of influenza may use sequences derived from the $V \| \mathrm{VH}$ gene, indicating that similar $\mathrm{VH}$ regions may be used by both anti-HA and anti-PC antibodies. By contrast, the VK sequences of anti-HA antibodies are very different from the VK sequences of anti-PC antibodies indicating that the L-chain is critical in determining specificity of these antibodies. Previous studies (Leon and Young, 1971; Andres et al., 1981; Hudak and Claflin, manuscript in preparation) have shown a correlation between L-chain type and fine specificity of $\mathrm{PC}$-binding. The $\mathrm{L}$-chain may contribute some contact residues or $\mathrm{L}$-chain may influence conformation of the H-chain and thus dictate specificity indirectly (Kabat, 1981). Chain recombination experiments between anti-HA antibodies and anti-PC antibodies may prove useful in further delineating the role of combinatorial association in generating antibody diversity.

Acknowledgements - I he authors are indebted to Drs Steven Clarke. Stuart Rudikoff and Martin Weigert for providing us with sequence information prior to publication. We thank Emma Williams for preparing the manuscript and Joan Christensen for assistance with Figs 3-5.

\section{REFERENCES}

Alexandru I. Kells D. I. C., Dorrington K. J. and Klein M. (1980) Non-covalent association of heavy and light chains of human IgG: studies using light chain labelled with a fluorescent probe. Molec. Immun. 17, 1351-1363.

Andres C. M., Maddalena A., Hudak S., Young N. M. and Claflin J. L. (1981) Anti-phosphocholine hybridoma antibodies. II. Functional analysis of binding sites within three antibody families. $J$. exp. med. 154, 1584-1598.

Askonas B. A. and Williamson A. R. (1968) Interchain disulphide bond formation in the assembly of immunoglobulin G. Biochem. $J .109,637-642$.

Barstad P., Hubert J., Hunkapiller M., Goetze A., Schilling J., Black B., Eaton B., Richards J., Weigert M. and Hood L. (1978) Immunoglobulins with hapten binding activity: structure-function correlations and genetic implications. Eur. J. Immun. 8, 497-503.

Bevan M. J. (1971) Interchain disulfide bond formation studied in two mouse myelomas which secrete immunoglobulin A. Eur. J. Immun. 1, 133-138.

Bluestone J. A., Krutzch H. C., Auchincloss H., Jr, Cazenave P.-A., Kindt T. J. and Sachs D. H. (1982) Antiidiotypes against anti-H-2 monoclonal antibodies: structural analysis of the molecules induced by in vito anti-idiotype treatment. Proc. natn. Acad. Sci. U.S.A. 79, $7847-7851$.

Bridges S. H. and Little J. R. (1971) Recovery of binding activity in reconstituted mouse myeloma proteins. Biochemistry 10, 2525-2530.

Capra J. D., Berek C. and Eichmann K. (1976) Structural studies on induced antibodies with defined idiotypic specificities. III. $N$-terminal amino acid sequence of the heavy and light chains of mouse anti-streptococcal antibodies-A5A, S8 and S117. J. Immun. 117, 7-10.

Chang S. P., Brown M. and Rittenberg M. B. (1982) Immunologic memory to phosphocholine. III. IgM in cludes a fine specificity population distinct from T15. $J$. Immun. 129, 1559-1562.

Claflin J. L. and Cubberly M. (1980) Clonal nature of the immune response to phosphocholine. VII. Evidence throughout inbred mice for molecular similarities among antibodies bearing the T15 idiotype. J. Immun. 125. $551-558$.

Clafin J. L. and Davie J. M. (1975) Specific isolation and characterization of antibody directed to binding site antigenic determinants. $J$. Immun. 114, 70-75.

Claflin J. L. and Rudikoff S. (1976) Uniformity in a clonal repertoire: a case for a germ-line basis of antibody diversity. Cold Spring Harb. Symp. quant. Biol. 41, $725-734$.

Clarke S. H., Claflin J. L. and Rudikoff S. (1982) Polymorphisms in immunoglobulin heavy chains suggesting gene conversion. Proc. natn. Acad. Sci. U.S.A. 79, 3280-3284

Crews S., Griffin J., Huang H., Calame K. and Hood L. (1981) A single $V_{H}$ gene segment encodes the immune response to phosphorylcholine: somatic mutation is correlated with the class of the antibody. Cell 25, 59-66.

de Preval $C$. and Fougereau M. (1977) Specific interaction between $V_{H}$ and $V_{L}$ regions of human monoclonal immunoglobulins. J. molec. Biol. 102, 657-678.

Early P., Huang H., Davies M., Calame K. and Hood L. (1980) An immunoglobulin $\mathrm{H}$ chain variable region gene is generated from three segments of DNA $-V_{H}, D, J_{H}$. Cell 19, 981-992.

Gcarhart P. J., Johnson N. D., Douglas R. and Hood L. (1981) IgG antibodies to phosphocholine exhibit more diversity than their IgM counterparts. Nature, Lond. 291, 29-34.

Gough N. M. and Bernard O. (1981) Sequences of the joining region genes for immunoglobulin chains and their role in generation of antibody diversity. Proc, natn. Acad. Sci. U.S.A. 78, 509-513.

Greenwood F. G.. Hunter W. M. and Glover J. S. (1963) The preparation of ${ }^{13}$ H-labelled human growth hormone of high specific radioactivity. Biochem. J. 89, 114-118. 
Grey H. M. and Mannik M. (1965) Specificity of recombination of $H$ and $L$ chains from human " G-myeloma proteins. $J$ exp $\mathrm{Med}$ 122, 619-632.

Hudak S. and Claflin J. L. (manuscript in preparation).

Kabat E. A. (1981) Gaps in our understanding of how specificity and complementary are generated. In $1 \mathrm{mmu}$ noglobulin Idiotypes (Edited by Janeway C., Sercarz E. E. and Wigzell H.) pp. 21-31. Academic Press, New York.

Klein M. C. Kortan C. Kells D. I. C. and Dorrington K. J. (1979) Equilibrium and kinetic aspects of the interaction of isolated variable and constant domains of light chain with the $\mathrm{Fd}^{\prime}$ fragment of immunoglobulin $\mathrm{G}$. Biochemistry 18, 1473-1481.

Kocher H. P., Berek C., Schreir M. H., Cosenza H. and Jaton J. (1980) Phosphorylcholine-binding hybridoma proteins of normal and idiotypically suppressed BALB/c mice. II. Variable region $N$-terminal amino acid sequences. Eur. J. Immun. 10, 264-267.

Kranz D. and Voss E. W. Ir (1981) Restricted reassociation of heavy and light chains from hapten-specific monoclonal antibodies, Proc, natn. Acad. Sci. U.S.A. 78. $5807-5811$

Kurosawa $Y$. and Tonegawa S. (1982) Organization, structure. and assembly of immunoglobulin heavy chain diversily DNA segments. J. exp. Med. 155, 201-218.

Laemmli U. K. (1970) Cleavage of structural proteins during the assembly of head of bacteriophage T4. Nature, Lond. 227, 680-685.

Leon M. and Young N. M. (1971) Specificity for phosphorylcholine of six murine myeloma proteins reactive with Pnewmococcus $C$ polysaccharide and $\beta$-lipoprotein. Biochemistry: 10, 1424-1429.

Manjula B. N., Glaudemans C. P. J., Mushinski E. B. and Potter M. (1976) Subunit interactions in mouse myeloma proteins with anti-galactan activity. Proc, natn. Acad. Sci. U.S.A. 73, 932-936.

Mushinski J. F. (1971) ; A half molecules: defective heavy chain mutants in mouse myeloma. J. Immun. 106, 41-50.

Padlan E. A. Davies D. R., Rudikoff S. and Potter M. (1976) Structural basis for the specificity of phosphorylcholine-binding immunoglobulins. Immunochemistry $13,945-949$.
Robinson E. A. and Appella E. (1979) Amino acid sequence of a mouse myeloma immunoglobulin heavy chain (MOPC 47A) with a 100-residue deletion, $y$. biol. Chom. 254, 11418-11430.

Rodwell J. D., Gearhart P. J. and Karush F. (1983) Restriction in IgM expression. IV. Affinity analysis of monoclonal anti-phosphorylcholine antibodies. $J . \mathrm{Im}$ mun. 130, 313-316.

Rothstein T. L. and Gefter M. L. (1983) Affinity analysis of idiotype-positive and idiotype-negative Ars-binding hybridoma proteins and Ars-immune sera. Mole's. Immen. 20, 161-168.

Rudikoff S., Giusti A. M., Cook W. D. and Scharli" M. D. (1982) Single amino acid substitution altering antigenbinding specificity. Proc. natn. Acad. SCt. U.S.4. 79, 1979-1983.

Scher A., Lord E and Cohn M. (1971) Reconstitution from subunits of the hapten binding sites and idiotypic determinants of mouse antiphosphorylcholine myelomis proteins. J. Immun. 107, 1226-1234.

Selsing E. and Storb U. (1981) Somatic mutation of immunoglobulin light chain variable-region genes. Cell 25 , 47.58.

Staudt L. M. and Gerhard W. (1983) Generation of antibody diversity in the immune response of GALB/C mice to influence virus hemagglutinin. $J$ exp. Med. 157. $687-704$.

Streefkerk D., Vrana M. and Glaudemans C. P. J. (1978) Binding studies on heavy-light chain recombinant hybrid immunoglobulins A derived from murine antfructofuranans. J. Immin. 120, $408-410$.

Wicker L. S., Guelde G., Sher I. and Kenny J. (1982) Antibodies from the Lyb-5- B cell subset predominate in the secondary $\operatorname{lgG}$ response to phosphocholine. I. Immuth. 129, $950-953$.

Wray W.. Boulikas T., Wray V. P. and Hancock R. (1981) Silver staining of proteins in polyacrylamide gels. Analy. Biochem. 118, 197-203.

Zack D. J.. Morrison S. L.. Cook W. D., Dackowski W. and Scharf M. D. (1981) Somatically generated mouse myeloma variants synthesizing IgA half-molecules $J$. axy. Med. 154, 1554-1569. 